\title{
The Gunnison's prairie dog structures a high desert grassland landscape as a keystone engineer
}

\author{
R. K. Bangert` \& C. N. Slobodchikoff \\ Department of Biological Sciences, Northern Arizona University, \\ P.O. Box 5640, Flagstaff AZ 86011, U.S.A.
}

(Received 25 October 1999, accepted 12 August 2000)

\begin{abstract}
The influence of landscape spatial structure on ecological processes has recently received much attention. Comparisons are made here between the spatial structure of grasslands, and active and extirpated Gunnison's prairie dog (Cynomys gunnisoni Hollister) towns at the Petrified Forest National Park, Arizona, U.S.A. The spatial structure of bare ground was quatified using a box-counting technique to extract landscape fractal dimensions, $D$, and bareground patch size. These landscapes are fractal, and active prairie dog towns had higher fractal dimensions, i.e. a more homogeneous spatial structure as $D$ approaches 2 , than inactive towns, which had higher fractal dimensions than unmodified grasslands. Morisita's index suggested that shrubs were more randomly distributed on prairie dog towns and more aggregated on grassland habitats. The different spatial distributions of bare ground and shrubs have the potential to influence resource distributions between these habitats for both prairie dogs and other fauna. Consequently, the presence of prairie dogs in these grasslands increases grassland landscape heterogeneity at large spatial scales, potentially enhancing beta diversity.
\end{abstract}

(C) 2000 Academic Press

Keywords: Arizona; Cynomys gunnisoni; high desert grasslands; fractals; Gunnison's prairie dog; landscape ecology; Morisita's index; Petrified Forest National Park

\section{Introduction}

The study of landscape ecology is concerned with the consequences of spatial structure and heterogeneity on ecological processes, e.g. plant and animal population dynamics, species interactions, community composition, and energy flows within and across boundaries (e.g. Wiens et al., 1985; Urban et al., 1987; Turner, 1989; Holling, 1992; Johnson et al., 1992b; Wiens et al., 1993b; Pickett \& Cadenasso, 1995). Much theoretical and empirical work has been done on the consequences of landscape structure on the dynamics and distribution of animal populations (Turchin, 1991; Milne et al., 1992; With \& Crist, 1995, 1996; With et al., 1997; With \& King, 1999) and animal resource utilization (O’Neill et al., 1988; Pearson et al., 1996). For example, in a simulation model, Holling et al. (1996) found that boreal forest structure determined the pattern of forest fire regime which in turn determined the pattern of boreal forest structure resulting in a self-perpetuating, self-organizing complex system. Moreover, this simulation model produced landscape features and fire properties similar to those found in real

^Author for correspondence. 
boreal forests (Holling et al., 1996). Even though landscapes are traditionally viewed at the scale of kilometers to hundreds of kilometers, a landscape can be as small as a prairie dog town or the home range of an insect and is a function of the scale important to the organism(s) of interest and their ecology (Wiens et al., 1986; Risser, 1987; Wiens, 1989; Wiens \& Milne, 1989; Kotliar \& Wiens, 1990; Turner \& Gardner, 1991).

In this study the choice of scale was directed by an interest in the Gunnison's prairie dog (Cynomys gunnisoni) as a landscape modifier. Since landscapes are viewed as complex, hierarchically structured, scale-dependent systems (Allen \& Starr, 1982; Meentemeyer \& Box, 1987; Urban et al., 1987; Turner, 1989; Kotliar \& Wiens, 1990), the resolution of this study considers landscape structure over a range of scales $(0.0625 \mathrm{~m}$ to $1 \mathrm{~m})$ up to the spatial extent (hundreds of metres between habitat types). Looking at the landscape from the perspective of a natural experiment allows us to study landscape ecology in a tractable way because landscapes are generally too large to manipulate, replicate, and thus randomize treatments (Diamond, 1986; Wiens \& Milne, 1989; Wiens et al., 1993a; Beier \& Noss, 1998), and manipulation at this scale, if logistically possible, may be unethical (Farnsworth \& Rosovsky, 1993).

Here, prairie dog activities were taken as the factor organizing landscape structure. Prairie dogs modify the surface of the landscape through their grazing activities. The effects of grazing by prairie dogs on non-woody plants has been well-documented (e.g. Bonham \& Lerwick, 1976; Detling \& Painter, 1983; Brizuela et al., 1986; Whicker \& Detling, 1988, 1993; Day \& Detling, 1994). Digging for seeds (Shalaway \& Slobodchikoff, 1988) appears to increase the patchiness of grasses on prairie dog colonies or conversely, the gap structure (bare ground patches) between grasses (pers. obs.). However, the effects prairie dogs have on the spatial structure of the landscape have not been studied. In this context prairie dogs might be classified as ecosystem engineers (Jones et al., 1994, 1997). Jones et al. (1994, 1997; see also Johnston, 1995) indicate the importance of landscape modification by animals in most ecosystems while acknowledging that the results of ecosystem engineering have rarely been explicitly studied (see also Lawton, 1994; Gurney \& Lawton, 1996). Ecosystem engineers are bottom-up forces structuring landscapes and communities, where their activities alter ecosystems in a consistent way that should result in landscapes that tend to similar states (Jones et al., 1994). Since prairie dog activities have a large impact on landscape structure, it is expected that there is a continuum of disturbance and spatial structure that in turn may influence the community structure and behaviour of other species present. If the influence of prairie dogs is strong then prairie dogs may be keystone species (Miller et al., 1994, 2000; Kotliar et al., 1999; see also Mills et al., 1993) or, more appropriately, keystone engineers (sensu Jones et al., 1994; Ceballos et al., 1999).

Recently, some authors have noted that many landscape-level studies (for review see Beier \& Noss, 1998) and most studies on the influence of prairie dogs on other animal communities were not conducted in a comparative manner, where prairie dog towns were compared with grasslands without prairie dogs (Stapp, 1998). These concerns are beginning to be addressed by asking the question: do prairie dogs have a significant effect on the spatial distribution of bare ground and shrubs, compared to that of the surrounding grassland? In this study we focused on shrubs and bare ground because these are the most conspicuous elements of this desert grassland landscape. This comparison sets the context for other comparative studies on the indirect responses of the arthropod community and beetle movement behaviour to prairie dog activities (Bangert \& Slobodchikoff, in review).

\section{Methods}

Study site

This work was conducted on the high desert grasslands of the Petrified Forest National Park (PEFO), Arizona, U.S.A. $\left(35^{\circ} \mathrm{N}\right.$ latitude; $110^{\circ} \mathrm{W}$ longitude). The elevation ranges 
from approximately $1620-1900 \mathrm{~m}$, with an average annual precipitation of $24.4 \mathrm{~cm}$ (range $=8 \cdot 6-40 \cdot 1$ ) and average high temperatures ranging from $0 \cdot 8^{\circ} \mathrm{C}$ in January to $23.5^{\circ} \mathrm{C}$ in July (from 65 years of unpublished weather data). Precipitation exhibits a single peak in July and August due to the summer south-west monsoonal phenomenon. The prairie dog towns in this study are characterized by a shrub-steppe community dominated by the shrubs Atriplex canescens Nutt. and Atriplex jonesii Standl., and the grasses Bouteloua gracilis Steud. and Hillaria jamesii Benth.

\section{Landscape modifier}

The Gunnison's prairie dog is a medium-sized ground squirrel in the family Sciuridae and is found on the Colorado Plateau and on high-altitude grasslands of western North America (Fitzgerald et al., 1994; Goodwin, 1995). Prairie dog activities are concentrated due to their colonial and social nature (Hoffmeister, 1986; Fitzgerald et al., 1994), making prairie dog colonies, or towns, conspicuous features of North American grassland ecosystems.

\section{Experimental design}

There were three treatment levels of natural manipulation (sensu Diamond, 1986) in this study: (1) habitats with no prairie dog influence (7 grasslands); (2) prairie dog towns after prairie dog removal from 50\% of the landscape by the plague in April 1995 (4 inactive towns); and (3) active prairie dog landscape modification (4 active towns). Conducting this study in a comparative manner, including recently extirpated colonies, should begin to satisfy the arguments that prairie dog studies are rarely comparative and prairie dog removal needs to be incorporated (Stapp, 1998).

This study was conducted during the months of June and July in 1996 and 1997. In 1996, landscape measurements of the fractal dimension of bare ground were taken at three active and three inactive prairie dog towns, where towns were separated by no less than $5 \mathrm{~km}$. At each of these six sites we also measured the landscape on the directly adjacent grassland no less than $100 \mathrm{~m}$ beyond the prairie dog/grassland boundary. In 1997, due to road closures within PEFO, one active and one inactive prairie dog town were studied, along with a distant grassland site, and increased the sample size of landscape measurements per site (1996: $n=15 ; 1997: n=30)$. These data were analysed with ANOVA, and alpha (0.05) was protected with a Bonferroni adjustment in any post hoc tests that were performed.

In 1996, shrub distributions were studied in one active town and one inactive town and their adjacent grasslands. In the case of shrub distributions, it was assumed that shrub distribution would not change in the short time since prairie dog extirpation, i.e. no effects due to prairie dog removal were expected. Any differences in bare ground structure between active and inactive prairie dog towns were assumed to be due to prairie dog activities.

\section{Landscape structure}

Landscape structure was quantified with the methods of fractal geometry, where fractal geometry quantifies the rate of change over a range of measurement scales. A boxcounting technique (Morse et al., 1985; Lovejoy et al., 1987; Wiens \& Milne, 1989) was used to measure the fractal dimension of bare ground on the three habitat types, where the fractal dimension, $D$, is given by:

$$
N(\delta)=k \delta^{-D}
$$


where $N$ is the number of boxes counted at a given box size $\delta$, and $k$ is some constant (based on Milne, 1988, 1991; Sugihara \& May, 1990). The number of boxes were counted within a randomly placed $1 \mathrm{~m}^{2}$ quadrat that met the criteria of at least $25 \%$ bare ground in any one box (Wiens \& Milne, 1989) at each of the five scales (box sizes). The quadrat was divided into 'boxes' with sides of $6 \cdot 25,12 \cdot 5,25,50$, and $100 \mathrm{~cm}$, where there were 256, 64, 16, 4, and 1 box, respectively, at each resolution. Following Wiens \& Milne (1989), bare ground is the cover of interest because this should facilitate Eleodes beetle movement. Because we were primarily interested in how a beetle perceives and interacts with the landscape (Bangert \& Slobodchikoff, in preparation), boxes were evaluated for the $>25 \%$ bare-ground criteria at beetle level and not by the canopy cover of the vegetation. The counts, $N$, and box sizes, $\delta$, were $\log _{10}$ transformed and the transformed box counts regressed against the transformed box sizes in order to solve for $D$ in equation (1) (Wiens \& Milne, 1989); the fractal dimension, $D$, is the slope of this regression (Mandelbrot, 1983; Milne, 1988). Technically, the fractal dimension is:

$$
-1(D)
$$

(Sugihara \& May, 1990). If the plot of $\log _{10} N v s . \log _{10} \delta$ is linear (large $r^{2}$ values) this is an indication that the fractal approach is integrating scale-dependent patterns across these scales (Wiens \& Milne, 1989).

When the fractal dimension of bare ground is $D=2$, bare ground fills the plane and $D$ is the familiar Euclidean exponent for an area (Milne, 1988). With values of $D<2$, the landscape becomes increasingly more complex as $D$ approaches 1 . As the values of $D$ fall the bare-ground plane is increasingly broken up by patches, rings, and arcs of grass (Johnson et al., 1992a). After the fractal dimension for each quadrat was derived, the three treatments (active, inactive, and grasslands) were analysed with ANOVA.

The question arises as to whether percent bare ground conveys the same information as the fractal dimension. As bare ground approaches $100 \%$, the fractal dimension converges on 2 by definition, i.e. bare ground is plane-filling. For example, Fig. 1 illustrates how a habitat pattern can cover $50 \%$ of the plane and have different fractal dimensions $(D=1.80$ vs. $D=1 \cdot 70)$ depending on the spatial structure of the habitat. On the real landscapes at PEFO a difference in fractal dimension of only 0.05 was significant. This analysis indicates that bare ground does not provide the same information that fractal dimension does. Fractal dimension, i.e. the arrangement of habitat, may therefore be more important to many organisms than simply the quantity of habitat. In this study, the predictions that active prairie dog towns will have the highest fractal dimension of bare ground, adjacent grassland habitats will have the lowest fractal dimension or exhibit the highest degree of complexity, and inactive prairie dog towns will be intermediate in fractal dimension resulting in a continuum of spatial complexity due to prairie dog activities were specifically studied.

Another measure of landscape structure is bare-ground patch size. The percent bare ground in each $1 \mathrm{~m}$ quadrat was converted to the number of bare-ground boxes with sides equal to $6 \cdot 25 \mathrm{~cm}$ (256 possible) and used as a measure of bare-ground patch size. Bare-ground patch size may be viewed as the relative connectedness of bare-ground, where large numbers of bare-ground boxes indicates large patches that tend to be connected.

\section{Shrubs}

In 1996 transects were established that crossed the prairie dog/grassland boundary at each of two prairie dog towns. There were 20 sampling points on the prairie dog town and 20 points on the grassland along each transect. Four sampling points on either side of the putative prairie dog/grassland boundary were removed from the analysis in order 


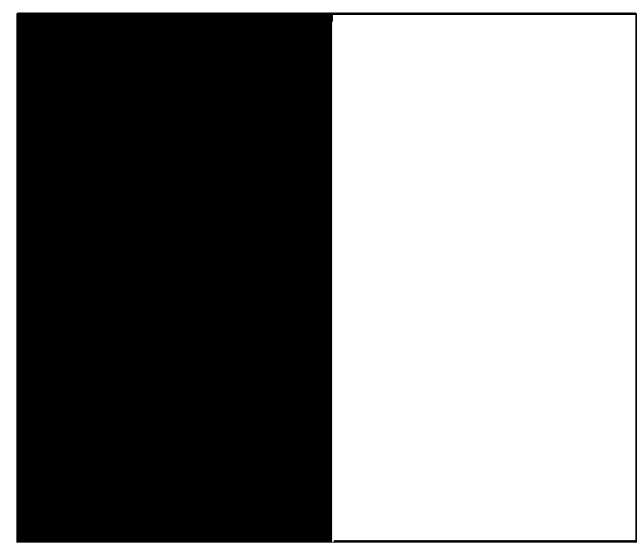

$$
\begin{aligned}
& \mathrm{N}(\delta)=\mathrm{K} \delta^{-\mathrm{D}} \\
& \mathrm{Black}=50 \% \\
& \mathrm{D}=1.80 \\
& r^{2}=0.9878
\end{aligned}
$$

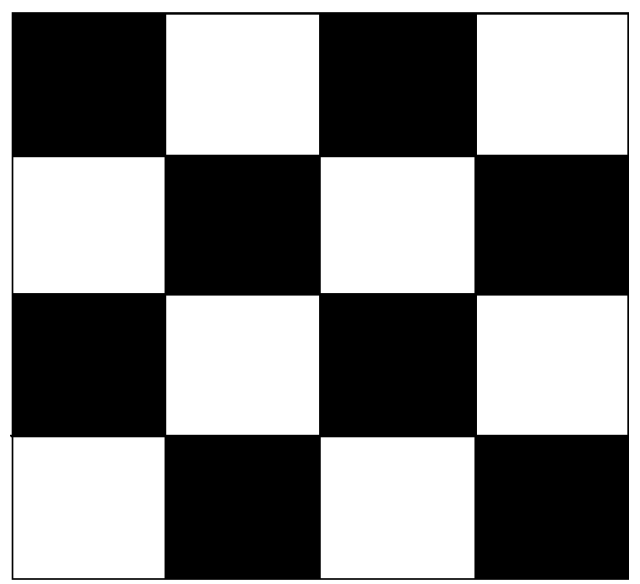

Black $=50 \%$

$\mathrm{D}=1 \cdot 70$

$r^{2}=0.9897$

Figure 1. The same amount of 'habitat' (50\% black cells) with different distributions has different fractal dimensions, $D$. The top drawing represents a simple pattern with a high fractal dimension whereas the lower drawing represents a more complex pattern with a lower fractal dimension. Differences in fractal dimension as small as 0.05 were significant in this study. This demonstrates that describing a landscape by its fractal dimension conveys more information than by its percent habitat cover alone.

to ensure that samples were well within the two treatments, respectively, in order to eliminate boundary effects. Shrubs were counted within a $3 \mathrm{~m}$ radius at each of 16 sampling points at $10 \mathrm{~m}$ intervals along the transect. A sliding window technique over a range of scales was employed, similar to that advocated by Plotnick et al. (1996), to calculate Morisita's index $\left(I_{M}\right)$ as a measure of aggregation (Hurlbert, 1990). The sliding window sizes ranged from $1,2, \ldots, 8$ sampling points. For example, shrubs were counted within a sliding window of $n$ sampling points, then the window of $n$ points was moved one point and counts made again. $I_{M}$ was then calculated at each resolution to examine the behaviour of shrub distributions across this range of scales (e.g. Hurlbert, 1990). $I_{M}$ is in the variance to mean ratio family of indices and its parametric form is:

$$
I_{M}=\left(\frac{X}{X-1}\right)\left(\frac{1}{\mu}\right)\left(\frac{\sigma^{2}}{\mu}(\mu-1)\right)
$$


where $X$ is the total number of individuals. For example, $I_{M}$ measures how many times more likely two shrubs will be in the same sample than they would be if shrubs were distributed at random. $I_{M}$ values were assessed with a $\chi^{2}$ test criterion, where $I_{M}$ values significantly greater than one indicate a departure from a random distribution towards aggregation (Hurlbert, 1990). At both sites all shrubs larger than $20 \mathrm{~cm}$ in crown diameter were counted.

\section{Results}

\section{Landscape structure}

The active prairie dog towns, inactive towns, and grasslands at Petrified Forest were fractal. In 1996 and 1997 there was a total of $2701 \mathrm{~m}$ quadrats measured for fractal dimension, across three treatments at 12 sites, with site regression $r^{2}$ values ranging from 0.9642 to 0.9993 ; all $p<0.0000$. In 1998 the fractal dimension of a single $5 \times 5 \mathrm{~m}$ grassland plot indicated that these grasslands were fractal over the range of scales from at least 0.0625 to $5 \mathrm{~m}\left(r^{2}=0.9992 ; p=0.0000\right)$, which included a subset of the scales at which prairie dogs interact with the spatial structure of these grasslands.

Prairie dogs exerted a substantial impact on landscape structure as measured by the fractal dimension of the distribution of bare ground. Both the active and inactive prairie dog-modified landscapes were significantly less complex $(D \rightarrow 2)$ than grasslands. The inactive prairie dog towns were intermediate between active towns and grassland habitats, indicating that the inactive towns are relaxing to some pre-prairie dog condition $\left(F_{2,267}=40 \cdot 42, p=0.0000\right.$; Fig. 2 , Table 1$)$. Moreover, the variances associated with these treatments exhibited the opposite pattern, whereby the active towns showed the lowest, inactive towns intermediate, and grasslands the highest variance (Table 1). The effect of prairie dog activities is consistent in increasing landscape fractal dimension.

Active prairie dog towns exhibited low variance in the size of bare-ground patches where these patches were consistently large (mean number of bare-ground box counts per quadrat at the $6 \cdot 25 \mathrm{~cm}$ resolution: $215 \cdot 2 \pm 36 \cdot 4$ S.D.; range: 116 to 256 ; Fig. 3 ).

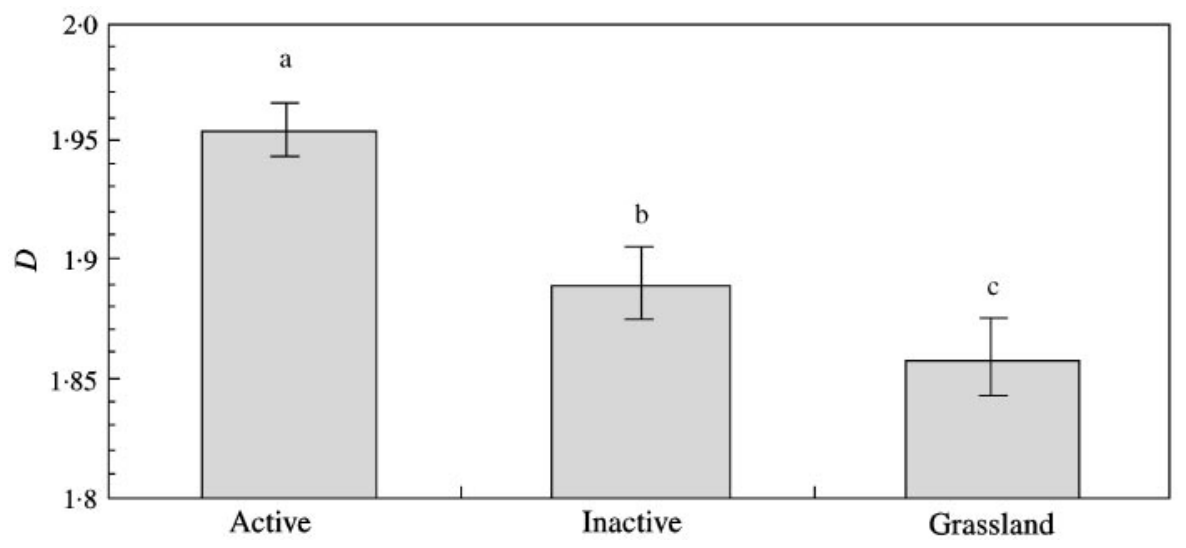

Figure 2. Prairie dog influence on landscape structure at the habitat level. Active prairie dog towns have significantly higher fractal dimensions than inactive prairie dog towns and grassland habitats. Inactive prairie dog town landscape structure is relaxing to that of the grasslands. Error bars represent 95\% confidence intervals and different letters indicate differences between treatments with a Bonferroni adjustment at a familywise error rate $=0 \cdot 05$. 
Table 1. ANOVA table with means and one standard deviation for the effects of prairie dogs on the fractal dimension of landscape structure and bare ground patch size

\begin{tabular}{|c|c|c|c|c|c|}
\hline & df. & SS & MS & $F$ & $p$ \\
\hline Fractal & 2 & $0 \cdot 4337$ & $0 \cdot 2168$ & $40 \cdot 42$ & $0 \cdot 0000$ \\
\hline Within & 267 & $1 \cdot 4322$ & $0 \cdot 0054$ & & \\
\hline Total & 269 & $1 \cdot 8658$ & & & \\
\hline Patch size & 2 & 168450 & 84225 & $48 \cdot 7$ & $0 \cdot 0000$ \\
\hline Within & 267 & 461727 & 1729 & & \\
\hline \multirow[t]{3}{*}{ Total } & 269 & 630178 & & & \\
\hline & \multicolumn{3}{|c|}{ Fractal } & \multicolumn{2}{|c|}{ Patch size } \\
\hline & \multicolumn{2}{|c|}{ mean $(n)$} & S.D. & mean $(n)$ & S.D. \\
\hline Active & \multicolumn{2}{|c|}{$1.9553(75)$} & $0 \cdot 0467$ & $215 \cdot 2(75)$ & $36 \cdot 36$ \\
\hline Inactive & \multicolumn{2}{|c|}{$1.8900(75)$} & $0 \cdot 0661$ & $171 \cdot 1(75)$ & 39.94 \\
\hline Grassland & \multicolumn{2}{|c|}{$1.8585(120)$} & $0 \cdot 0892$ & $155 \cdot 3(120)$ & $45 \cdot 45$ \\
\hline
\end{tabular}

Conversely, there was large variance in the size of these patches on grassland habitats where patches can be both large and small (mean number of bare-ground box counts per quadrat at the $6.25 \mathrm{~cm}$ resolution: $155.3 \pm 45 \cdot 5$ S.D.; range: 25 to 256 ) and inactive towns were intermediate $(171 \cdot 1 \pm 39.9$ S.D.; range: 91 to 251$)$. All three habitat types had significantly different bare-ground patch sizes $\left(F_{2,267}=48.7, p=0.0000\right.$; Fig. 3, Table 1). Both the fractal dimension and box counts of bare ground indicated that grassland habitats are more structurely complex than active prairie dog towns and that the inactive towns are intermediate in spatial structure (Figs $2 \& 3$, Table 1).

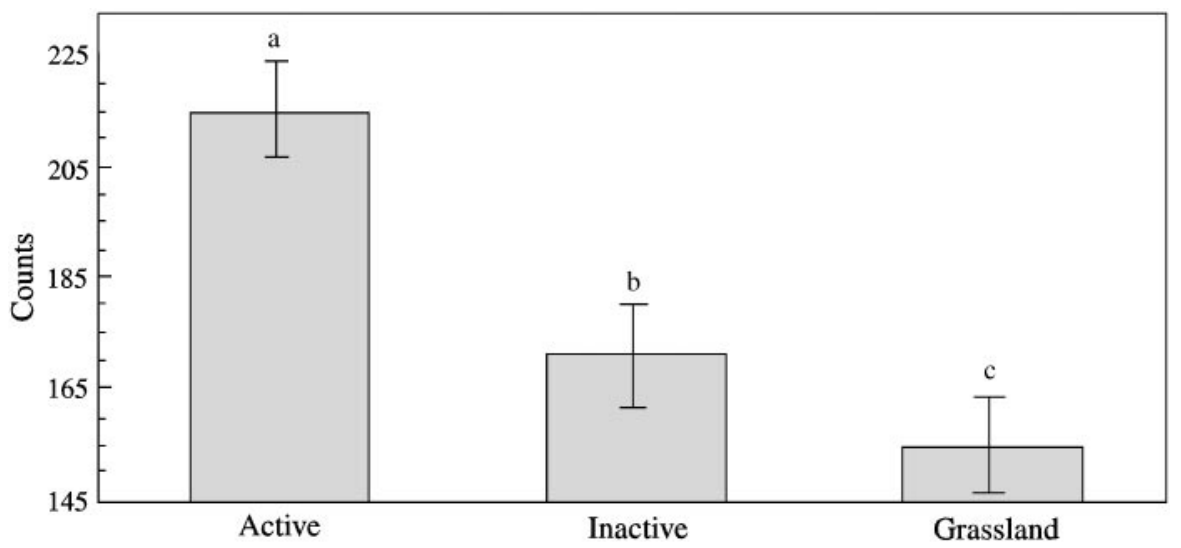

Figure 3. Bare ground patch size, measured by mean box counts per $1 \mathrm{~m}$ quadrat at the $6.25 \mathrm{~cm}$ box size, was largest on active towns and smallest on grassland habitats, but the variance in patch size exhibited the opposite pattern. Error bars represent $95 \%$ confidence intervals and different letters indicate differences between treatments with a Bonferroni adjustment at a familywise error rate $=0 \cdot 05$. 


\section{Shrub distribution}

In 1996, a sliding window of shrub counts over a series of resolutions (1-8 sample points) was used to calculate Morisita's index $\left(I_{M}\right)$ at two prairie dog towns and their adjacent grasslands, respectively. Twenty-nine of $30 I_{M}$ were significantly greater than unity indicating that the distribution of shrubs on the overall landscape was aggregated. This index also indicated that shrubs were more aggregated on grassland habitats than on prairie dog towns (Fig. 4), even though there were significantly more shrubs on the active town (prairie $\operatorname{dog}=48$, grassland $=26 ; \chi^{2}=6.54$, df. $=2, p<0.05$ ). There were equal numbers of shrubs between the two habitats at the inactive town (40 each), but the aggregation pattern measured by $I_{M}$ was similar to that at the active town. The prairie dog influence on shrub distribution was consistent over a range of scales even though these two prairie dog towns each had a different shrub species component.

\section{Discussion}

Most of the rigorous comparative work on the effects of prairie dog activities has focused on plant physiological responses such as water status (Archer \& Detling, 1986; Day \& Detling, 1994), nutrient and mineral concentrations (Brizuela et al., 1986; Jaramillo \& Detling, 1988; Holland \& Detling, 1990), and morphology due to grazinginduced genetic polymorphisms (Detling \& Painter, 1983; Painter et al., 1989; also see Whicker \& Detling, 1988, 1993 for an overview and references therein). As the discipline of landscape ecology has matured, more ecological studies are considering the influence of the spatial structure of habitats on ecological processes. This has been demonstrated theoretically and empirically (e.g. movement: Slobodchikoff \& Doyen, 1977; Crist et al., 1992; dispersal success: Gardner et al., 1989; With, 1994a,

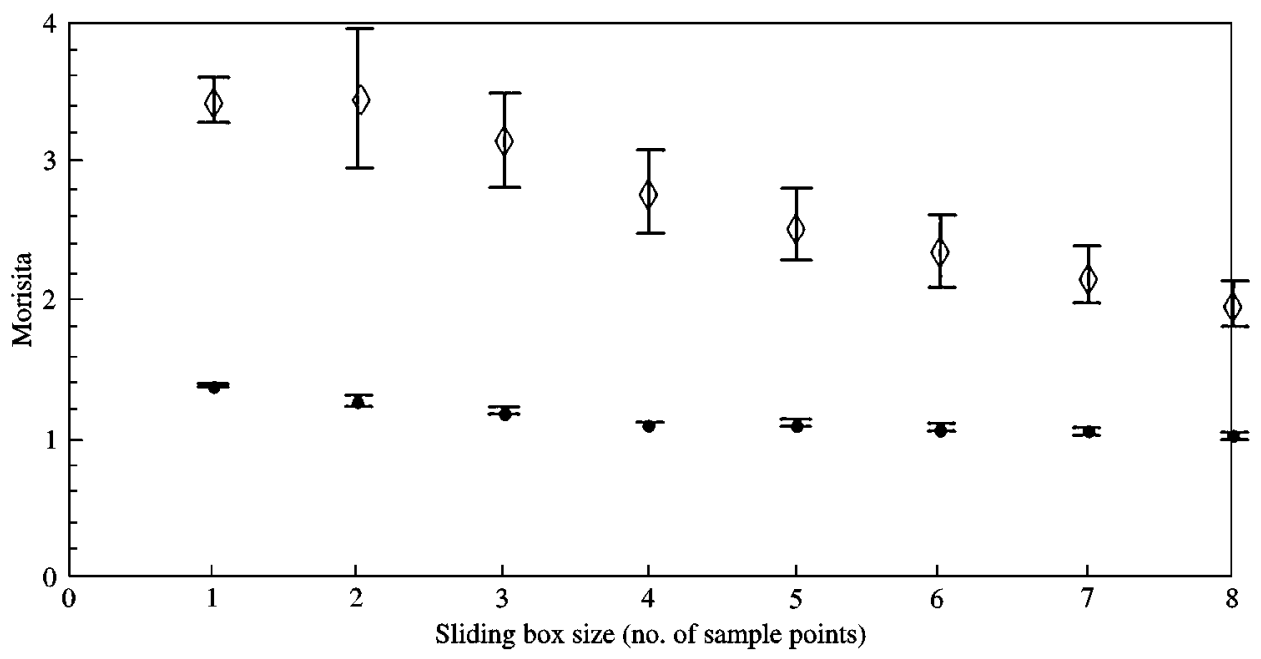

Figure 4. The Morisita index is a modified coefficient of dispersion and is an indication of a departure from randomness. Values increasingly greater than one indicates that the distribution of individuals is becoming increasingly aggregated. The mean Morisita index from two prairie dog towns and two grasslands for the 1996 transect data of shrub counts is presented. At all eight scales of resolution the grassland habitats exhibited greater aggregation of shrubs and the prairie dog towns exhibited a comparatively random distribution of shrubs. Error bars are \pm 1 S.E. $\diamond$ Grassland; $\bullet$ Prairie dog. 
1994b, 1997; population dynamics: Crist \& Wiens, 1995; With \& Crist, 1995; forest fire regime: Holling et al., 1996). Until this study there has been no work on the spatial structure of bare ground or the distribution of shrubs induced by prairie dogs.

Gunnison's prairie dog at the Petrified Forest National Park in north-eastern Arizona had a significant and predictable impact on the spatial structure of the landscape compared to the surrounding grasslands. Landscapes modified by prairie dog were less complex $(D \rightarrow 2)$ and less variable than were adjacent grasslands. Inactive prairie dog colonies were intermediate and appear to be returning slowly to the spatial condition of the grasslands. The pattern of the distribution of shrubs was different between prairie dog-modified and unmodified grassland landscapes. There were both quantitative and qualitative differences, with the overall pattern suggesting that shrubs were less aggregated on prairie dog towns.

The differences in landscape structural attributes between prairie dog colonies and the surrounding grasslands may have direct and indirect influences on the distribution of resources for both prairie dogs and other organisms. Direct influences on the distribution of resources may occur when shrubs and grasses are the actual resource. Indirect influences will be on resources that are mobile such as seeds and detritus. Prairie dog activities, such as grazing, reduce the cover of grass, which in turn lowers the boundary layer of air. With a lower boundary layer, particles such as seeds and detritus will tend to move along the surface and accumulate around obstructions (e.g. clumps of grass and shrubs; Reichman, 1984; Price \& Reichman, 1987). Consequently, prairie dog activities such as digging for seeds (Shalaway \& Slobodchikoff, 1988) will then be concentrated at the base of the grass clumps, thus further reducing the size of individual clumps of grass (pers. obs.). This results in a habitat that has relatively few small bunches of grass interspersed with large, consistently-sized open areas of bare ground. These results provide the testable hypothesis that predicts mobile resources, such as seeds, will tend to be clumped with a low variance in distribution on prairie dog towns.

By quantifying landscape structure, predictions about other ecological processes can be made. For some arthropods (e.g. mobile ground-dwelling animals; With et al., 1999) bare ground may act as both habitat and non-habitat. For flightless detritivorous tenebrionid beetles, clumps of grass may tend to 'collect' resources moving along the bare ground plane and bare ground should therefore facilitate beetle movement and access to these resources. Consequently, it is predicted that beetle movement behaviour will be enhanced in prairie dog towns and that beetles will preferentially select the prairie dog-modified habitat because access to clumped resources should be more predictable (Bangert \& Slobodchikoff, in review). Hence, the importance of quantifying landscape structure as a result of prairie dog activities is to guide predictions about other ecological processes.

Prairie dogs create a unique habitat within the grassland ecosystem by altering surface spatial structure, which has the potential to influence the distribution of resources for prairie dogs and other animals. Not only might the distribution of resources be affected, but the ability to access resources and population distributions of some species may be affected as well. For example, the distribution of resources can determine prairie dog social structure and their social structure can change as the distribution of resources change (Slobodchikoff, 1984). Prairie dog activities add heterogeneity at the landscape level, and this heterogeneity is potentially important to a wide variety of animals. Therefore, prairie dog-modified habitats may be an important landscape component in western grasslands. Since the turn of the century the area of the landscape occupied and modified by prairie dogs has decreased by an estimated 98\% (Marsh, 1984, cited in Oldemeyer et al., 1993) due to habitat destruction and active extermination. This extreme loss of a unique habitat component has undoubtedly influenced ecological processes. This study is a first comparative step between prairie dog towns and the adjacent grasslands that will form the foundation for future studies on the 
impact of prairie dogs on biodiversity, community, and behavioural processes in this ecosystem. With this approach taken in future studies, the status of prairie dogs as a 'keystone genus' will be more rigorously addressed. The prairie dog influence on structural habitat heterogeneity is strong, thus reinforcing the need for special conservation attention in order to ensure the maintenance of biodiversity and ecological processes associated with prairie dog colonies.

We would like to thank Drs V. J. Meretsky, P. W. Price, and three anonymous reviewers for comments that greatly improved this paper. We also appreciate the efforts of M. Hellickson, W. Grether, and M. DePoy at the Petrified Forest National Park for encouraging and facilitating ecological work at the Park. This work was in part funded by grants provided by the Petrified Forest Museum Association to RKB.

\section{References}

Allen, T.H.F. \& Starr, T.B. (1982). Hierarchy: Perspectives for Ecological Complexity. Chicago: University of Chicago Press.

Archer, S. \& Detling, J.K. (1986). Evaluation of potential herbivore mediation of plant water status in a North American mixed-grass prairie. Oikos, 47: 287-291.

Bangert, R.K. \& Slobodchikoff, C.N. (in review). Keystone engineers and animal movement: prairie dogs indirectly affect beetle movement behaviour.

Beier, P. \& Noss, R.F. (1998). Do habitat corridors provide connectivity? Conservation Biology, 12: $1241-1252$.

Bonham, C.D. \& Lerwick, A. (1976). Vegetation changes induced by prairie dogs on shortgrass range. Fournal of Range Management, 29: 221-225.

Brizuela, M.A., Detling, J.K. \& Cid, M.S. (1986). Silicon concentration of grasses growing in sites with different grazing histories. Ecology, 67: 1098-1101.

Ceballos, G., Pacheco, J. \& List, R. (1999). Influence of prairie dogs (Cynomys ludovicianus) on habitat heterogeneity and mammalian diversity in Mexico. Fournal of Arid Environments, 41: 161-172.

Crist, T.O. \& Wiens, J.A. (1995). Individual movements and estimation of population size in darkling beetles (Coleoptera: Tenebrionidae). Fournal of Animal Ecology, 64: 733-746.

Crist, T.O., Guertin, D.S., Wiens, J.A. \& Milne, B.T. (1992). Animal movement in heterogeneous landscapes: an experiment with Eleodes beetles in shortgrass prairie. Functional Ecology, 6: 536-544.

Day, T.A. \& Detling, J.K. (1994). Water relations of Agropyron smithii and Bouteloua gracilis and community evapotranspiration following long-term grazing by prairie dogs. American Midland Naturalist, 132: 381-392.

Detling, J.K. \& Painter, E.L. (1983). Defoliation responses of western wheatgrass populations with diverse histories of prairie dog grazing. Oecologia, 57: 65-71.

Diamond, J. (1986). Overview: Laboratory experiments, field experiments, and natural experiments. In: Diamond, J. \& Case, T.J. (Eds), Community Ecology, pp. 3-22. New York: Harper and Row.

Farnsworth, E.J. \& Rosovsky, J. (1993). The ethics of ecological field experimentation. Conservation Biology, 7: 463-472.

Fitzgerald, J.P., Meaney, C.A. \& Armstrong, D.M. (1994). Mammals of Colorado. Denver: Denver Museum of Natural History and University Press of Colorado.

Gardner, R.H., O’Neill, R.V., Turner, M.G. \& Dale, V.H. (1989). Quantifying scale-dependent effects of animal movement with simple percolation models. Landscape Ecology, 3: 217-227.

Goodwin, T.H. (1995). Pliocene-Pleistocene biogeographic history of prairie dogs, genus Cynomys (Sciuridae). Fournal of Mammalogy, 76: 100-122.

Gurney, W.S.C. \& Lawton, J.H. (1996). The population dynamics of ecosystem engineers. Oikos, 76: 273-283.

Hoffmeister, D.F. (1986). Mammals of Arizona. Tucson: University of Arizona Press and the Arizona Game and Fish Department. 
Holland, E.A. \& Detling, J.K. (1990). Plant response to herbivory and belowground nitrogen cycling. Ecology, 71: 1040-1049.

Holling, C.S. (1992). Cross-scale morphology, geometry, and dynamics of ecosystems. Ecological Monographs, 62: 447-502.

Holling, C.S., Peterson, G., Marples, P., Sendzimir, J., Redford, K., Gunderson, L. \& Lambert, D. (1996). Self-organization in ecosystems: lumpy geometries, periodicities and morphologies. In: Walker, B. \& Steffen, W. (Eds), Global Change and Terrestrial Ecosystems, pp. 346-384. Cambridge: Cambridge University Press.

Hurlbert, S.H. (1990). Spatial distribution of the montane unicorn. Oikos, 58: 257-271.

Jaramillo, V.J. \& Detling, J.K. (1988). Grazing history, defoliation, and competition: effects on shortgrass production and nitrogen accumulation. Ecology, 69: 1599-1608.

Johnson, A.R., Milne, B.T. \& Wiens, J.A. (1992a). Diffusion in fractal landscapes: simulations and experimental studies of tenebrionid beetle movements. Ecology, 73: 1968-1983.

Johnson, A.R., Wiens, J.A., Milne, B.T. \& Crist, T.O. (1992b). Animal movements and population dynamics in heterogeneous landscapes. Landscape Ecology, 7: 63-75.

Johnston, C.A. (1995). Effects of animals on landscape pattern. In: Hansson, L., Fahrig, L. \& Merriam, G. (Eds), Mosaic Landscapes and Ecological Processes, pp. 58-80. London: Chapman and Hall.

Jones, C.G., Lawton, J.H. \& Shachak, M. (1994). Organisms as ecosystem engineers. Oikos, 69: 373-386.

Jones, C.G., Lawton, J.H. \& Shachak, M. (1997). Positive and negative effects of organisms as physical ecosystem engineers. Ecology, 78: 1946-1957.

Kotliar, N.B. \& Wiens, J.A. (1990). Multiple scales of patchiness and patch structure: a hierarchical framework for the study of heterogeniety. Oikos, 59: 253-260.

Kotliar, N.B., Baker, B.W., Whicker, A.D. \& Plumb, G. (1999). A critical review of assumptions about the prairie $\operatorname{dog}$ as a keystone species. Environmental Management, 24: 177-192.

Lawton, J.H. (1994). What do species do in ecosystems? Oikos, 71: 367-374.

Lovejoy, S., Schertzer, D. \& Tsonis, A.A. (1987). Functional box-counting and multiple elliptical dimensions in rain. Science, 235: 1036-1038.

Mandelbrot, B.B. (1983). The Fractal Geometry of Nature. New York: W. H. Freeman and Company. 468 pp.

Meentemeyer, V. \& Box, E.O. (1987). Scale effects in landscape studies. In: Turner, M.G. (Ed.), Landscape Heterogeneity and Disturbance, pp. 15-34. New York: Springer-Verlag.

Miller, B., Ceballos, G. \& Reading, R. (1994). The prairie dog and biotic diversity. Conservation Biology, 8: 677-681.

Miller, B., Reading, R., Hoogland, J., Clark, T., Ceballos, G., List, R., Forrest, S., Hanebury, L., Manzano, P., Pacheco, J. \& Uresk, D. (2000). The role of prairie dogs as a keystone species: response to Stapp. Conservation Biology, 14: 318-321.

Mills, L.S., Soule, M.E. \& Doak, D.F. (1993). The keystone-species concept in ecology and conservation. BioScience, 43: 219-224.

Milne, B.T. (1988). Measuring the fractal geometry of landscapes. Applied Mathematics and Computation, 27: 67-79.

Milne, B.T. (1991). The utility of fractal geometry in landscape design. Landscape and Urban Planning, 21: 81-90.

Milne, B.T., Turner, M.G., Wiens, J.A. \& Johnson, A.R. (1992). Interactions between the fractal geometry of landscapes and allometric herbivory. Theoretical Population Biology, 41: 337-353.

Morse, D.R., Lawton, J.H., Dodson, M.M. \& Williamson, M.H. (1985). Fractal dimension of vegetation and the distribution of arthropod body lengths. Nature, 314: 731-733.

Oldemeyer, J.L., Biggins, D.E., Miller, B.J. \& Crete, R. (Eds) (1993). Proceedings of the symposium on the management of prairie dog complexes for the reintroduction of the black-footed ferret. Washington, D.C.: U.S. Department of the Interior Fish and Wildlife Service.

O’Neill, R.V., Milne, B.T., Turner, M.G. \& Gardner, R.H. (1988). Resource utilization scales and landscape pattern. Landscape Ecology, 2: 63-69.

Painter, E.L., Detling, J.K. \& Steingraeber, D.A. (1989). Grazing history, defoliation, and frequency-dependent competition: effects on two North American grasses. American Fournal of Botany, 76: 1368-1379. 
Pearson, S.M., Turner, M.G., Gardner, R.H. \& O’Neill, R.V. (1996). An organism-based perspective of habitat fragmentation. In: Szaro, R.C. \& Johnston, D.W. (Eds), Biodiversity in Managed Landscapes: Theory and Practice, pp. 77-95. New York: Oxford University Press.

Pickett, S.T.A. \& Cadenasso, M.L. (1995). Landscape ecology: spatial heterogeneity in ecological systems. Science, 269: 331-334.

Plotnick, R.E., Gardner, R.H., Hargrove, W.W., Prestegaard, K. \& Perlmutter, K. (1996). Lacunarity analysis: a general technique for the analysis of spatial pattern. Physical Review E, 53: 5461-5468.

Price, M.V. \& Reichman, O.J. (1987). Distribution of seeds in Sonoran desert soils: implications for heteromyid rodent foraging. Ecology, 68: 1797-1811.

Reichman, O.J. (1984). Spatial and temporal variation of seed distributions in Sonoran Desert soils. Fournal of Biogeography, 11: 1-11.

Risser, P.G. (1987). Landscape ecology: state of the art. In: Turner, M.G. (Ed.), Landscape Heterogeneity and Disturbance, pp. 3-14. New York: Springer-Verlag.

Shalaway, S. \& Slobodchikoff, C.N. (1988). Seasonal changes in the diet of the Gunnison's prairie dog. Fournal of Mammalogy, 69: 835-841.

Slobodchikoff, C.N. (1984). Resources and the evolution of social behavior. In: Price, P.W., Slobodchikoff, C.N. \& Gaud, W.S. (Eds), A New Ecology: Novel Approaches to Interactive Systems, pp. 227-251. New York: John Wiley and Sons.

Slobodchikoff, C.N. \& Doyen, J.T. (1977). Effects of Ammophila arenaria on sand dune arthropod communities. Ecology, 58: 1171-1175.

Stapp, P. (1998). A reevaluation of the role of prairie dogs in Great Plains grasslands. Conservation Biology, 12: 1253-1259.

Sugihara, G. \& May, R.M. (1990). Applications of fractals in ecology. Trends in Ecology and Evolution, 5: 79-86.

Turchin, P. (1991). Translating foraging movements in heterogeneous environments into the spatial distribution of foragers. Ecology, 72: 1253-1266.

Turner, M.G. (1989). Landscape ecology: the effect of pattern on process. Annual Reveiw Ecology and Systematics, 20: 171-197.

Turner, M.G. \& Gardner, R.H. (Eds) (1991). Quantitative Methods in Landscape Ecology: The Analysis and Interpretation of Landscape Heterogeneity. New York: Springer-Verlag. $536 \mathrm{pp}$.

Urban, D.L., O’Neill, R.V. \& Shugart, H.H. (1987). Landscape ecology. BioScience, 37: 119-127.

Whicker, A.D. \& Detling, J.K. (1988). Ecological consequences of prairie dog disturbances: prairie dogs alter grassland patch structure, nutrient cycling, and feeding-site selection by other herbivores. BioScience, 38: 778-785.

Whicker, A.D. \& Detling, J.K. (1993). Control of grassland ecosystem processes by prairie dogs. In: Oldemeyer, J.L., Biggins, D.E., Miller, B.J. \& Crete, R. (Eds), Proceedings of the symposium on the management of prairie dog complexes for the reintroduction of the black-footed ferret, pp. 18-27. Washington, D.C.: U.S. Department of the Interior, Fish and Wildlife Service.

Wiens, J.A. \& Milne, B.T. (1989). Scaling of 'landscapes' in landscape ecology, or, landscape ecology from a beetle's perspective. Landscape Ecology, 3: 87-96.

Wiens, J.A. (1989). Spatial scaling in ecology. Functional Ecology, 3: 385-397.

Wiens, J.A., Crawford, C.S. \& Gosz, J.R. (1985). Boundary dynamics: a conceptual framework for studying landscape ecosystems. Oikos, 45: 421-427.

Wiens, J.A., Addicott, J.F., Case, T.J. \& Diamond, J. (1986). Overview: the importance of spatial and temporal scale in ecological investigations. In: Diamond, J. \& Case, T.J. (Eds), Community Ecology, pp. 145-153. New York: Harper and Row.

Wiens, J.A., Crist, T.O. \& Milne, B.T. (1993a). On quantifying insect movements. Environmental Entomology, 22: 709-715.

Wiens, J.A., Stenseth, N.C., Van Horn, B. \& Ims, R.A. (1993b). Ecological mechanisms and landscape ecology. Oikos, 66: 369-380.

With, K.A. (1994a). Ontogenetic shifts in how grasshoppers interact with landscape structure: an analysis of movement patterns. Functional Ecology, 8: 477-485.

With, K.A. (1994b). Using fractal analysis to assess how species perceive landscape structure. Landscape Ecology, 9: 25-36.

With, K.A. (1997). The application of neutral landscape models in conservation biology. Conservation Biology, 11: 1069-1080. 
With, K.A. \& Crist, T.O. (1995). Critical thresholds in species' responses to landscape structure. Ecology, 76: 2446-2459.

With, K.A. \& Crist, T.O. (1996). Translating across scales: simulating species distributions as the aggregate response of individuals to heterogeneity. Ecological Modelling, 93: 125-137.

With, K.A. \& King, A.W. (1999). Dispersal success on fractal landscapes: a consequence of lacunarity thresholds. Landscape Ecology, 14: 73-82.

With, K.A., Gardner, R.H. \& Turner, M.G. (1997). Landscape connectivity and population distributions in heterogeneous environments. Oikos, 78: 151-169.

With, K.A., Cadaret, S.J. \& Davis, C. (1999). Movement responses to patch structure in experimental fractal landscapes. Ecology, 80: 1340-1353. 